\title{
Can cardiovascular magnetic resonance prompt early cardiovascular/ rheumatic treatment in autoimmune rheumatic diseases? Current practice and future perspectives
}

\author{
Sophie I. Mavrogeni ${ }^{1}$. Petros P. Sfikakis ${ }^{2}$. Theodoros Dimitroulas ${ }^{3}$ - Loukia Koutsogeorgopoulou ${ }^{4} \cdot$ Gikas Katsifis $^{5}$. \\ George Markousis-Mavrogenis ${ }^{1} \cdot$ Genovefa Kolovou$^{1} \cdot$ George D. Kitas ${ }^{6}$
}

Received: 30 January 2018 / Accepted: 3 March 2018 / Published online: 7 March 2018

(c) Springer-Verlag GmbH Germany, part of Springer Nature 2018

\begin{abstract}
Life expectancy in autoimmune rheumatic diseases (ARDs) remains lower compared to the general population, due to various comoborbidities. Cardiovascular disease (CVD) represents the main contributor to premature mortality. Conventional and biologic disease-modifying antirheumatic drugs (DMARDs) have considerably improved long-term outcomes in ARDs not only by suppressing systemic inflammation but also by lowering CVD burden. Regarding atherosclerotic disease prevention, EULAR has recommended tight disease control accompanied by regular assessment of traditional CVD risk factors and lifestyle changes. However, this approach, although rational and evidence-based, does not account for important issues such as myocardial inflammation and the long asymptomatic period that usually proceeds clinical manifestations of CVD disease in ARDs before or after the diagnosis of systemic disease. Cardiovascular magnetic resonance (CMR) can offer reliable, reproducible and operator independent information regarding myocardial inflammation, ischemia and fibrosis. Some studies suggest a role for CMR in the risk stratification of ARDs and demonstrate that oedema/fibrosis visualisation with CMR may have the potential to inform cardiac and rheumatic treatment modification in ARDs with or without abnormal routine cardiac evaluation. In this review, we discuss how CMR findings could influence anti-rheumatic treatment decisions targeting optimal control of both systemic and myocardial inflammation irrespective of clinical manifestations of cardiac disease. CMR can provide a different approach that is very promising for risk stratification and treatment modification; however, further studies are needed before the inclusion of CMR in the routine evaluation and treatment of patients with ARDs.
\end{abstract}

Keywords Rheumatic diseases - Cardiovascular magnetic resonance imaging · Cardiovascular diseases

\section{Introduction}

Systemic lupus erythematosus (SLE), rheumatoid arthritis (RA), the spondyloarthritides [psoriatic arthritis (PsA) and ankylosing spondylitis (AS)], systemic sclerosis ( $\mathrm{SSc}$ ), Sjögren's syndrome (SS), mixed connective tissue disease (MCTD), inflammatory myopathies [dermatomyositis (DM), polymyositis (PM) and inclusion body myositis (IBM)], vasculitis of large, medium and small vessels are included in autoimmune rheumatic diseases (ARDs) with great potential

Disclaimer: No part of the manuscript contains copied texts or graphics.

Sophie I. Mavrogeni

soma13@otenet.gr

Extended author information available on the last page of the article of cardiovascular disease (CVD), due to both traditional and novel risk factors namely systemic inflammation and autoimmune dysregulation $[1,2]$.

The introduction of targeted treatment has led to significant reductions in disease-associated mortality; however, the life expectancy of ARD patients still remains lower compared to that of the general population [1-3], mainly due to increased incidence of CVD [4-8]. Any structure of cardiac tissue can be affected and patients may present with valvular, myocardial and/or pericardial inflammation, macro- and micro-coronary artery disease (CAD), vasculitis, systolic/ diastolic heart failure, myocardial fibrosis, as well as pulmonary arterial hypertension (PAH) [9-11]. Irrespective of aetiology, CVD symptoms in ARDs are subtle and usually are attributed to the underlying systemic disease. Clinically overt cardiac signs indicate advanced myocardial involvement and carry a poor prognosis [11]. 
CMR, a non-invasive CV imaging modality that does not utilize ionizing radiation can provide reliable, reproducible and operator independent information regarding CV function and myocardial tissue characteristics (inflammation, perfusion defects, fibrosis). It came recently in the diagnostic arena as a valuable tool for the differential diagnosis of various types of CVD in ARDs. CMR is the only noninvasive imaging modality that can reliably differentiate myocardial inflammation (positive oedema imaging with concurrent subepicardial or intramyocardial fibrosis) from myocardial ischemia-fibrosis (positive or negative oedema imaging depending on disease acuity with concurrent subendocardial or transmural fibrosis in the territory of the involved coronary artery), both commonly found in ARDs [12].

The aim of the current article is to provide an overview of the recommendations for prevention and treatment of CVD in ARDs and suggest how CMR findings can affect antirheumatic treatment decisions targeting to optimal control of both systemic and myocardial inflammation.

\section{Research strategy}

A MedLine, Embase and Scopus search was performed according to published guidance on narrative reviews [13] using the following terms: systemic autoimmune diseases, autoimmune rheumatic diseases, cardiovascular involvement, myocarditis, cardiac magnetic resonance, immunosuppressive treatment, systemic lupus erythematosus, systemic sclerosis, vasculitis, rheumatoid arthritis, ankylosing spondylitis. Original research papers and review articles focusing on the effect of immunosuppressive treatment on myocardial and cardiac disease evaluated by CMR in patients with ARDs up to December 2017 were selected to be included in this review. Publications not in English and data from ongoing research were excluded.

\section{Current treatment practices for patients with ARDs and CVD}

\section{Primary prevention of CVD}

Given the increased risk of premature atherosclerosis observed even in patients without traditional risk factors, primary prevention is crucial [14]. Several medications with anti-inflammatory properties have also been considered appropriate for the management of CVD in ARDs. Diseasemodifying antirheumatic drugs (DMARDs) were shown to associate with reduced progression of atherosclerosis in RA [15-17]. Improvement in inflammatory joint disease using anti-TNF- $\alpha$ therapies has also been associated with a reduction in cardiac events, further supporting the use of these disease-modifying agents $[18,19]$.

Recently, an update for clinicians was issued by the European League against Rheumatism (EULAR) with the aim of introducing CVD risk management recommendations and primary prevention strategies for patients with inflammatory joint disease [20].

\section{Management of cardiac rhythm disturbances in ARDs}

Cardiac rhythm disturbances are common in almost all ARDs with CV involvement. In RA, a major cause of sudden cardiac death (SCD) is coronary artery disease (CAD). In SLE, sinus tachycardia, atrial fibrillation and SCD during acute coronary syndromes are the commonest cardiac arrhythmias. In SSc, non-sustained ventricular tachycardia was described in 7-13\%, while SCD is reported in 5-21\% of unselected patients with SSc [21]. Their treatment is based on the underlying pathogenesis and is similar to their management in non-ARD patients [22, 23].

\section{Management of PAH}

ARD-related-PAH is not uncommon, especially within SSc patients who must be under diligent surveillance with annual screening including echocardiography [24]. Prevalence of asymptomatic PAH in SLE was reported to be $10.8 \%$, with a female-to-male ratio of 10:1 [25] Immune-mediated vasculopathy is observed in a small subset of patients with SLE-PAH and cyclophosphamide with low dose of steroids are of important value [26, 27]. Although ARD-related PAH confers higher mortality rates compared to idiopathic or other types of PAH, recent studies with novel targeted therapies have demonstrated a trend towards improvement of outcomes in this population [28-30].

\section{How can CMR prompt early CV treatment of ARDs?}

\section{Current practice and future perspectives}

Guidelines proposed by EULAR are based on the fact that $\mathrm{CV}$ involvement in ARDs is influenced by the classic CV risk factors, mimics the ebb and flow of systemic inflammation and can be positively affected by their tight control. This approach, although rational and evidence-based, does not account for some important issues such as the following: 
1. Cardiac disease may exist for a prolonged period before the diagnosis of an ARD is established [31].

2. The increased incidence of HF in patients with ARDs cannot be completely explained solely by CAD [32].

3. The potential adverse effects of some DMARDs on the $\mathrm{CV}$ system have not been adequately evaluated to safely recommend them in this context [33].

4. The role of myocardial inflammation independent of systemic inflammation has not been definitively established [34], as the majority of ARD patients with suspected CVD are assessed with echocardiography, which is incapable of characterizing pathological processes in $\mathrm{CV}$ tissues (e.g. inflammatory and/or fibrotic processes) [33-35].

5. CVD has been detected in numerous studies with ARDs, even if the patients were asymptomatic, the disease is quiescent [36] or in treatment naïve patients with ARDs [37]. Notably, there is some preliminary evidence from individual case reports to suggest that CVD can be the first and only indication of the presence of an ARD [3739].

CMR can answer to these queries, because it can reliably assess:

(a) myocardial ischemia and/or subendocardial/transmural fibrosis due to either CAD or coronary microvascular disease [36-40],

(b) epicardial, diffuse and/or focal myocardial fibrosis due to inflammation and/or cardiomyopathies [36-40],

(c) disease acuity either due to CAD or to myo-pericardial inflammation [36-41],

(d) extent and disease acuity of vascular inflammation [42] and

(e) causal pathologic processes behind silent/overt HF or rhythm disturbances $[43,44]$.

Apart from its use as the reference standard for the assessment of $\mathrm{CV}$ structure and function, CMR is the ideal technique for $\mathrm{CV}$ tissue characterization, due to its excellent spatial resolution. The two most commonly evaluated parameters are longitudinal relaxation time (T1) and transverse relaxation time (T2). T2 imaging can offer qualitative or semiquantitative information about myocardial oedema using the ratio of myocardial vs skeletal signal intensity. Recently, a true quantitative approach of myocardial oedema using T2 mapping has been proposed. T1 imaging can be used for perfusion evaluation (first pass assessment) or for fibrosis assessment 15 min post gadolinium injection (late enhanced imaging: LGE). The unique additional clinical utility of CMR compared to echocardiography is the use of LGE for the detection of focal fibrosis due to myocardial infarction (MI), myocarditis or cardiomyopathies (Fig. 1).

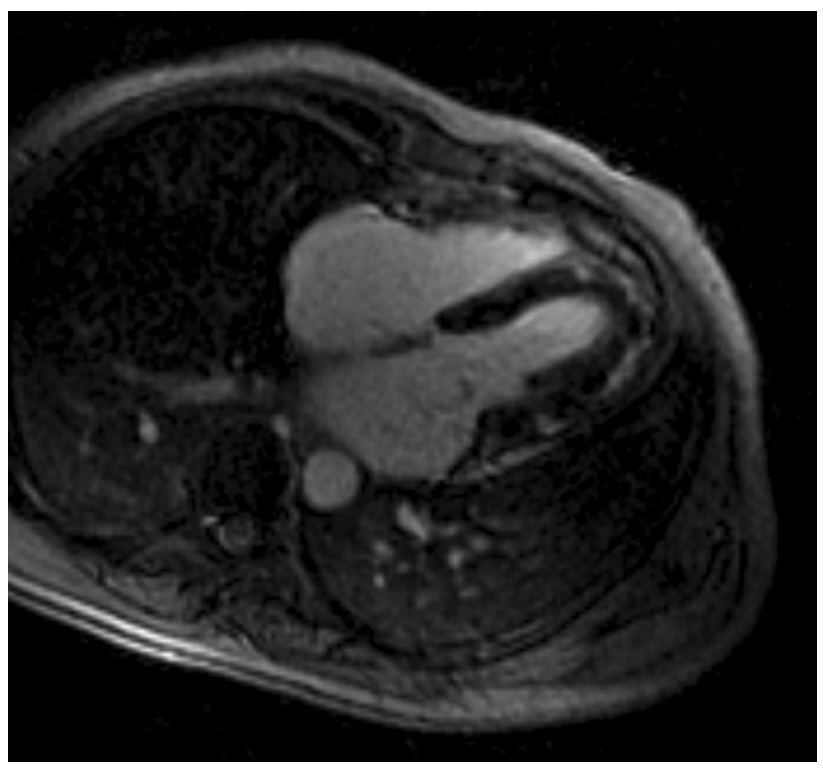

Fig. 1 Late gadolinium enhanced images showing patchy fibrosis in the interventricular septum, apex and lateral wall of LV in a patient with SLE myocarditis

LGE is based on the differences of signal intensity between scarred and normal myocardium to generate image contrast. This technique, although of great utility for detecting replacement myocardial fibrosis, is incapable of visualising diffuse myocardial fibrosis. To overcome this limitation, another CMR imaging technique called T1 mapping (native/ pre-contrast and post contrast) and extracellular volume (ECV) measurement has been developed and enables identification of myocardial fibrosis, also otherwise undetectable by currently used circulating biomarkers [45]. The use of T1/T2 mapping indices has demonstrated that patients with ARDs have higher T1 and T2 mapping values (more diffuse fibrosis and myocardial oedema) compared to controls, with most significant differences between patients and controls in native $\mathrm{T} 1$ and $\mathrm{T} 2$ mapping values, which are independent of the presence of LGE [46] (Fig. 2). Taking all together, CMR represents an excellent tool for assessment of the various guises of CVD disease in ARDs [46].

There are only a few studies supporting a role for CMR in the risk stratification of CVD in patients with ARDs. A previous study by our group documented that CMR can detect early silent CV lesions, assess disease acuity and reliably evaluate the effect of both cardiac and rheumatic medication on the CV system, due to its capability of performing tissue characterization [46]. In another study, the CMR findings of 246 ARD patients with typical cardiac symptoms $(n=146)$ or atypical cardiac symptoms $(n=100)$ were retrospectively evaluated. CMR in symptomatic ARD patients with normal echocardiographic findings assessed disease acuity and identified vasculitis, myocarditis, and myocardial infarction 
Fig. 2 Abnormal native (pre) (left) and post contrast (right) $\mathrm{T} 1$ mapping in a patient with SSc without evidence of positive LGE. Native T1 mapping $=1200 \mathrm{~ms}$ (nor$\mathrm{mal}<1050)$. PC T1 mapping $=246 \mathrm{~ms}($ normal $>350)$

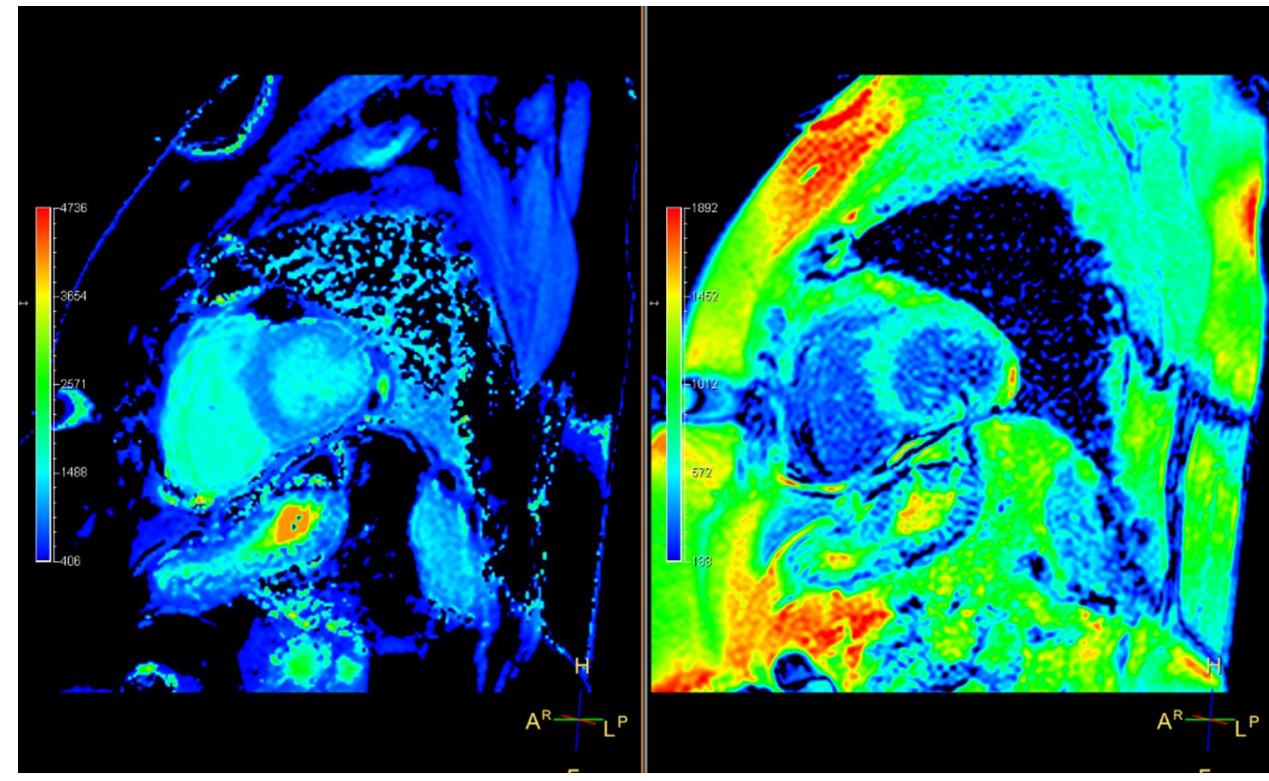

that influenced the $\mathrm{CV}$ risk stratification of ARD patients [36]. Furthermore, occult CMR lesions, including myocardial oedema, myocarditis, diffuse subendocardial fibrosis and myocardial infarction were not unusual in treatment naïve ARDs and may be reversed with appropriate treatment [37]. Additionally, stress CMR can detect silent myocardial Raynaud phenomena in patients with ARDs and known peripheral Raynaud phenomena and can motivate the early initiation of treatment with calcium channel blockers [47].

\section{Management of specific ARDs and potential role of CMR in treatment decision making}

\section{Systemic lupus erythematosus}

In SLE, the treatment of heart involvement depends on the severity of its clinical presentation [48]. CMR can be of additional value in SLE patients with atypical cardiac symptoms/signs and normal echocardiographic findings, because it can assess occult cardiac lesions including myocarditis, myocardial infarction and vasculitis, while prompting both rheumatic and cardiac treatment modifications in the process [49]. Recently, the use of native T1 and T2 mapping allowed not only the recognition of lupus myocarditis, but also the evaluation of cardiac response to anti-inflammatory treatment [50]. Furthermore, even in SLE patients with quiescent disease and normal cardiac function, low grade myocardial inflammation may be detected, which requires initiation of immunosuppressive treatment [51], although the benefits of such a strategy need to be evaluated in properly designed, long-term studies.

\section{Rheumatoid arthritis}

Traditional DMARDs either as monotherapy or in combination with anti-TNF- $\alpha$ agents are extremely effective in RA [52]. The capability of CMR to capture early tissue changes allow the early detection of pathophysiologic processes leading to HF in RA, such as myocardial inflammation and myocardial perfusion defects, due to either macrovascular (coronary artery disease) or microvascular (vasculitis) disease and facilitate the timely treatment [53].

In RA patients, CMR has already documented that myocardial inflammation/fibrosis correlated with RA disease activity and alterations in myocardial structure known to precede clinical HF [54]. Myopericarditis with atypical presentation, diagnosed with CMR in RA patients in clinical remission, may precede relapses of RA. At 1 year follow-up, RA patients with a history of myocarditis have a higher frequency of disease relapse and may develop HF [39].

The administration of tocilizumab (TCZ) was associated with LV improvement in RA patients, as assessed by CMR, which correlated with reduction in RA disease activity [44]. Additionally, TCZ significantly increased LVEF and decreased LVMI associated with disease activity [55]. Finally, the chronic use of hydroxyl-chloroquine may result in acquired lysosomal storage disorder, leading to a drug-induced cardiomyopathy; this is characterized by concentric hypertrophy and rhythm disturbances, is associated with increased incidence of adverse clinical outcomes and increased mortality and can be diagnosed by CMR [56]. However, we should mention that this complication is extremely rare in clinical practice. 


\section{Ankylosing spondylitis}

CMR using the classic protocols including function, oedema and fibrosis can offer additional information about myocardium in AS [57]. However, it may miss diffuse intramyocardial fibrosis, undetectable by LGE, due to technical limitations. Myocardial extracellular volume fraction (ECV), quantified by CMR T1 mapping, was associated with the degree of disease activity and can potentially be used as a marker for disease monitoring and personalised treatment [58].

\section{Systemic sclerosis/scleroderma}

Myocardial fibrosis is the hallmark of CVD in SSc, leading to heart failure, rhythm disturbances, PAH [59] and treatment is mainly symptomatic [60-62]. CMR may reveal severe CVD in early, asymptomatic diffuse SSc with normal routine cardiac evaluation, presenting either as myocardial inflammation or as severe reduction of myocardial perfusion rate index (MPRI) and diffuse fibrosis with further deterioration in the long-term follow-up [63]. Furthermore, myocardial abnormalities detected by CMR were associated with impaired strain parameters, disease activity and severity in SSc patients and therefore, CMR is useful in the treatment evaluation of SSc patients [64]. In this context, Pieroni et al. documented that myocarditis is a common finding in SSc with recent-onset cardiac involvement and its early diagnosis allows the timely start an immunosuppressive treatment leading to cardiac damage prevention in most cases [65].

\section{Vasculitides}

\section{Takayasu arteritis (TA)}

Almost all TA patients improve after treatment. However, various studies have shown inconsistent results [66-70]. An integrated CMR evaluation of TA not only provides good delineation of vessel wall thickening, but can also offer information about ventricular function, myocardial scarring, and has the potential to identify those TA at highest risk, allowing early start of treatment [71].

CMR in TA provides good delineation of vessel wall thickening and can assess ventricular function, myocardial scarring, and silent myocardial infarction. In addition, it can potentially identify patients most at risk for complications, prompting the initiation of early preventative therapy $[71,72]$.

\section{Giant cell arteritis (GCA)}

Half of GCA patients have cardiac disease; however, myocardial infarction is a rare or underdiagnosed complication $[70,73]$. CMR may also reveal myocarditis, a rare but serious complication in GCA that needs aggressive immunosuppressive therapy to avoid LV dysfunction [74].

\section{Kawasaki disease (KD)}

KD may present with myopericarditis and concurrent coronary artery aneurysms (CAA) developing in approximately $15-25 \%$ of untreated cases leading to both short- and long-term morbidity and mortality. The early application of immunoglobulin has modified the phenotype of KD. However, CAAs, myocardial inflammation and myocardial infarction are still life-threatening complications [75].

CMR offers important clinical information during both the acute and chronic phase of KD. In the acute phase, it can identify myocardial inflammation, microvascular disease, myocardial infarction, deterioration of left ventricular function, changes of the coronary artery lumen and vessel wall, which may in turn lead to cardiac and/or autoimmune treatment modifications. During the chronic phase, CMR might be of value for risk stratification and also treatment guidance [75].

\section{Eosinophilic granulomatosis with polyangiitis (eGPA)}

In eGPA the prevalence of cardiac disease varies between 15 and $55 \%$ of cases and represents the most frequent cause of death, accounting for $50 \%$ of all deaths $[76,77]$. A CMR study targeting to detect cardiac lesions and monitor treatment efficacy in EGPA with cardiac involvement revealed myocardial edema in $87.8 \%$, perfusion defects in $54.5 \%$ and late gadolinium enhancement (LGE) indicative of replacement fibrosis in all. Improvement after treatment was observed in $81 \%$ of them (in $11 \%$ completely remission and in 35\% evolution to global fibrosis) [78].

CMR has also documented that the lack of or inadequate duration of noncorticosteroid immunosuppressive treatment was an independent factor of cardiac involvement in EGPA and the extent of myocardial damage was associated with shorter duration of noncorticosteroid immunosuppressive treatment [79].

Furthermore, patients with eGPA in clinical remission showed increased incidence of CV involvement, demonstrated by lower LVEF, signs of active inflammation, presence of interstitial and replacement fibrosis and intraventricular thrombosis [80]. Additionally, in patients with active eGPA, CMR enabled the detection of cardiac involvement when cardiac symptoms were not present [81]. Another 
study recommended that CMR evaluation should be performed in all antineutrophil cytoplasmic antibody (ANCA)associated vasculitides with sustained remission, even if symptoms are absent and ECG is normal, for treatment risk stratification [82].

\section{CMR in PAH}

PAH may complicate various ARDs such as SSc, SLE, MCTD and RA. While selected patients with ARD-PAH may be candidates for lung transplantation, outcomes are less favourable than for idiopathic PAH, due to comorbidities and complications associated with ARDs [83]. The currently used diagnostic approach include transthoracic echocardiography and cardiac catheterisation.

There are no studies investigating the role of CMR in the assessment of PAH in ARDs. However, there is a systematic review evaluating the clinical yield of CMR findings in the prognostication of PAH. Among eight studies (539 patients) that investigated 21 different CMR findings, $\mathrm{RV}$ ejection fraction was found to be the strongest and most well-established predictor of mortality in PAH. In addition, increased RV volumes and decreased LV end-diastolic volume at baseline were found to be associated with a higher mortality risk in PAH patients [84]. Furthermore, because of lower measurement variability, CMR is more cost saving in PAH medication trials than echocardiography [85].

The effect of sildenafil in addition to conventional treatment of PAH in patients with SLE and SSc has been previously evaluated with CMR and found that the combination reduced the RV mass and improved cardiac function and exercise capacity in patients with PAH, WHO functional class III [86]. Additionally, combination therapy with ambrisentan and tadalafil was evaluated with CMR and was found to significantly improve hemodynamics, RV function, and functional status in treatment-naive patients with $\mathrm{SSc}-\mathrm{PAH}$; as such, it may represent a very effective therapy for this patient population [87].

\section{How can CMR prompt early diagnosis and initiation of cardiac treatment in ARDs?}

It has been already well documented through the ESC guidelines that every morphologic or functional change in myocardium, detected by any diagnostic technique, should motivate early start of ACE-inhibitors and b-blocker. This means that early information provided by CMR, even in patients with normal systolic function, can be used to change risk stratification and motivate early start of cardiac medication [88].

\section{How can CMR prompt early initiation or modification of antirheumatic treatment in ARDs?}

Currently, in patients with virus-negative chronic myocarditis or inflammatory cardiomyopathy, the beneficial effect of immunosuppressive treatment leading to LVEF improvement was documented [89]. Furthermore, another prospective study of immunosuppression for giant cell myocarditis (GCM) confirmed previous retrospective case reports supporting that such therapy improves long-term survival [90]. These publications offer a good reason to organize studies regarding the early treatment of myocardial inflammation in ARDs, irrespective of the systolic function and the status of systemic disease, if the CMR indices are indicative of myocardial inflammation.

The early detection of myocardial inflammation, even if the underlying disease seems quiescent, gives to rheumatology a powerful weapon to directly intervene on myocardial inflammation using new powerful immunosuppressive anti-inflammatory strategies and follow-up their direct effect on myocardium. However, at the moment, evidence-based results, established through short and long-term multi-center studies are still missing. Therefore, we need at least three levels of evidence to document the necessity of additive antirheumatic treatment in ARD patients with CMR evidence of myocardial inflammation:

1. Association studies from registries with adequate phenotype, treatment and outcome data.

2. Longitudinal long-term observational studies monitoring ARD patients who have been/have not been treated with additive antirheumatic medication, based on CMR findings.

3. Randomized controlled trials of antirheumatic treatment/ not treatment, based on CMR findings alone, with longterm outcomes.

\section{Conclusion}

CMR allows for the early detection of various CV pathophysiologic phenomena occurring in ARDs. Numerous preliminary studies indirectly suggest a promising role for CMR in prompting modifications of treatment in patients with ARDs and CV involvement. Although the role of cardiac treatment is established for early morphologic or functional cardiac changes, clear guidelines for rheumatic treatment are at the moment supported only by sporadic reports. Therefore, further research is required before definitive indications for rheumatic treatment modification based on CMR findings can be confidently issued for this patient population. 
Author contributions SM: responsible for conceiving and manuscript writing. PPS: literature searching and manuscript writing. TD: literature searching and manuscript writing. LK: literature searching and manuscript writing. GK: literature searching and manuscript writing. GMM: literature searching and manuscript writing. GK: literature evaluation and writing supervision. GDK: literature evaluation and writing supervision.

\section{Compliance with ethical standards}

Conflict of interest There is no conflict of interest for any of the authors.

Ethical approval This article does not contain any studies with human participants or animals performed by any of the authors.

Research involving human participants and/or animals N/A. It is a review study.

Informed consent N/A. It is a review study.

\section{References}

1. Goldblatt F, O'Neill SG (2013) Clinical aspects of autoimmune rheumatic diseases. Lancet 382(9894):797-808

2. Hollan I, Meroni PL, Ahearn JM, Cohen Tervaert JW, Curran S, Goodyear CS, Hestad KA, Kahaleh B, Riggio M, Shields K, Wasko MC (2013) Cardiovascular disease in autoimmune rheumatic diseases. Autoimmun Rev 12(10):1004-1015

3. Pohl D, Benseler S (2013) Systemic inflammatory and autoimmune disorders. Handb Clin Neurol 112:1243-1252

4. Björnådal L, Yin L, Granath F, Klareskog L, Ekbom A (2004) Cardiovascular disease a hazard despite improved prognosis in patients with systemic lupus erythematosus: results from a Swedish population based study 1964-95. J Rheumatol 31(4):713-719

5. Lee KS, Kronbichler A, Eisenhut M, Lee KH, Shin JI (2018) Cardiovascular involvement in systemic rheumatic diseases: an integrated view for the treating physicians. Autoimmun Rev 17(3):201-214. https://doi.org/10.1016/j.autrev.2017.12.001

6. Kitas GD, Gabriel SE (2011) Cardiovascular disease in rheumatoid arthritis: state of the art and future perspectives. Ann Rheum 70:8-14

7. Sherer Y, Shoenfeld Y (2006) Mechanisms of disease: atherosclerosis in autoimmune diseases. Nat Clin Pract Rheumatol 2:99-106

8. Aviña-Zubieta JA, Choi HK, Sadatsafavi M, Etminan M, Esdaile JM, Lacaille D (2008) Risk of cardiovascular mortality in patients with rheumatoid arthritis: a meta-analysis of observational studies. Arthritis Rheumatol 59:1690-1697

9. Symmons DP, Gabriel SE (2011) Epidemiology of CVD in rheumatic disease, with a focus on RA and SLE. Nat Rev Rheumatol 7(7):399-408

10. Gasparyan AY (2012) Cardiovascular risk and inflammation: pathophysiological mechanisms, drug design, and targets. Curr Pharm Des 18:1447-1449

11. Dimitroulas T, Giannakoulas G, Karvounis H, Garyfallos A, Settas L, Kitas GD (2014) Micro- and macrovascular treatment targets in scleroderma heart disease. Curr Pharm Des 20(4):536-544

12. Mavrogeni S, Karabela G, Gialafos E, Spiliotis G, Pentazos G, Mylona M, Panopoulos S, Plastiras S, Kolovou G, Stavropoulos E, Boutsikou M, Kitas G, Sfikakis PP (2014) Clinical queries addressed in patients with systemic autoimmune diseases.
Can cardiovascular magnetic resonance give the final solution? Inflamm Allergy Drug Targets 13(5):335-338

13. Gasparyan AY, Ayvazyan L, Blackmore H, Kitas GD (2011) Writing a narrative biomedical review: considerations for authors, peer reviewers, and editors. Rheumatol Int 31(11):1409-1417. https:// doi.org/10.1007/s00296-011-1999-3 Epub 2011 Jul 29.

14. Roman MJ, Salmon JE (2007) Cardiovascular manifestations of rheumatologic diseases. Circulation 116:2346-2355

15. Choi HK, Hernan MA, Seeger JD, Robins JM, Wolfe F (2002) Methotrexate and mortality in patients with rheumatoid arthritis: a prospective study. Lancet 359:1173-1177

16. Westlake SL, Colebatch AN, Baird J, Kiely P, Quinn M, Choy E, Ostor AJ, Edwards CJ (2010) The effect of methotrexate on cardiovascular disease in patients with rheumatoid arthritis: a systematic literature review. Rheumatology 49:295-307

17. Guin A, Chatterjee Adhikari M, Chakraborty S, Sinhamahapatra P, Ghosh A (2013) Effects of disease modifying anti-rheumatic drugs on subclinical atherosclerosis and endothelial dysfunction which has been detected in early rheumatoid arthritis: 1-year follow-up study. Semin Arthritis Rheumatol 43:48-54

18. Low AS, Symmons DP, Lunt M, Mercer LK, Gale CP, Watson KD, Dixon WG, Hyrich KL, British Society for Rheumatology Biologics Register for Rheumatoid Arthritis (BSRBR-RA) and the BSRBR Control Centre Consortium (2017) Relationship between exposure to tumour necrosis factor inhibitor therapy and incidence and severity of myocardial infarction in patients with rheumatoid arthritis. Ann Rheum Dis 76(4):654-660

19. Peters MJ, van Sijl AM, Voskuyl AE, Sattar N, Smulders YM, Nurmohamed MT (2012) The effects of tumor necrosis factor inhibitors on cardiovascular risk in rheumatoid arthritis. Curr Pharm Des 18:1502-1511

20. Agca R, Heslinga SC, Rollefstad S, Heslinga M, McInnes IB, Peters MJ, Kvien TK, Dougados M, Radner H, Atzeni F, Primdahl J, Södergren A, Wallberg Jonsson S, van Rompay J, Zabalan C, Pedersen TR, Jacobsson L, de Vlam K, Gonzalez-Gay MA, Semb AG, Kitas GD, Smulders YM, Szekanecz Z, Sattar N, Symmons DP, Nurmohamed MT (2017) EULAR recommendations for cardiovascular disease risk management in patients with rheumatoid arthritis and other forms of inflammatory joint disorders: 2015/2016 update. Ann Rheum Dis 76(1):17-28

21. Seferović $\mathrm{PM}^{1}$, Ristić AD, Maksimović R, Simeunović DS, Ristić GG, Radovanović G, Seferović D, Maisch B, Matucci-Cerinic M (2006) Cardiac arrhythmias and conduction disturbances in autoimmune rheumatic diseases. Rheumatology 45(Suppl 4):iv39-iv42

22. Prasad M, Hermann J, Gabriel SE, Weyand CM, Mulvagh S, Mankad R, Oh JK, Matteson EL, Lerman A (2015) Cardiorheumatology: cardiac involvement in systemic rheumatic disease. Nat Rev Cardiol 12:168-176

23. Villa-Forte A, MandelL BF (2011) Cardiovascular disorders and rheumatic disease. Rev Esp Cardiol 64:809-817

24. Khanna D, Gladue H, Channick R, Chung L, Distler O, Furst DE, Hachulla E, Humbert M, Langleben D, Mathai SC, Saggar R, Visovatti S, Altorok N, Townsend W, FitzGerald J, McLaughlin VV, Scleroderma Foundation and Pulmonary Hypertension Association (2013) Recommendations for screening and detection of connective tissue disease-associated pulmonary arterial hypertension. Arthritis Rheumatol 65(12):3194-3201

25. Xia YK, Tu SH, Hu YH, Wang Y, Chen Z, Day HT, Ross K (2013) Pulmonary hypertension in systemic lupus erythematosus: a systematic review and analysis of 642 cases in Chinese population. Rheumatol Int 33(5):1211-1217

26. Sanchez O, Sitbon O, Jaïs X, Simonneau G, Humbert M (2006) Immunosuppressive therapy in connective tissue diseases-associated pulmonary arterial hypertension. Chest 130(1):182-189 
27. Sugawara E, Kato M, Hisada R, Oku K, Bohgaki T, Horita T, Yasuda S, Atsumi T (2017) Treatment of vasodilator-resistant mixed connective tissue disease-associated pulmonary arterial hypertension with glucocorticoid and cyclophosphamide. Intern Med 56(4):445-448

28. Gaine S, Chin K, Coghlan G, Channick R, Di Scala L, Galiè N, Ghofrani HA, Lang IM, McLaughlin V, Preiss R, Rubin LJ, Simonneau G, Sitbon O, Tapson VF, Hoeper MM (2017) Selexipag for the treatment of connective tissue disease-associated pulmonary arterial hypertension. Eur Respir J 50(2):1602493

29. Coghlan JG, Galiè N, Barberà JA, Frost AE, Ghofrani HA, Hoeper MM, Kuwana M, McLaughlin VV, Peacock AJ, Simonneau G, Vachiéry JL, Blair C, Gillies H, Miller KL, Harris JHN, Langley J, Rubin LJ, AMBITION Investigators (2017) Initial combination therapy with ambrisentan and tadalafil in connective tissue disease-associated pulmonary arterial hypertension (CTD-PAH): subgroup analysis from the AMBITION trial. Ann Rheum Dis 76(7):1219-1227

30. Kowal-Bielecka O, Fransen J, Avouac J, Becker M, Kulak A, Allanore Y, Distler O, Clements P, Cutolo M, Czirjak L, Damjanov N, Del Galdo F, Denton CP, Distler JHW, Foeldvari I, Figelstone K, Frerix M, Furst DE, Guiducci S, Hunzelmann N, Khanna D, Matucci-Cerinic M, Herrick AL, van den Hoogen F, van Laar JM, Riemekasten G, Silver R, Smith V, Sulli A, Tarner I, Tyndall A, Welling J, Wigley F, Valentini G, Walker UA, Zulian F, MüllerLadner U, EUSTAR Coauthors (2017) Update of EULAR recommendations for the treatment of systemic sclerosis. Ann Rheum Dis 76(8): 1327-1339

31. Urowitz MB, Gladman DD, Anderson NM, Su J, Romero-Diaz J, Bae SC, Fortin PR, Sanchez-Guerrero J, Clarke A, Bernatsky S, Gordon C, Hanly JG, Wallace DJ, Isenberg D, Rahman A, Merrill J, Ginzler E, Alarcón GS, Fessler BF, Petri M, Bruce IN, Khamashta M, Aranow C, Dooley M, Manzi S, Ramsey-Goldman R, Sturfelt G, Nived O, Steinsson K, Zoma A, Ruiz-Irastorza G, Lim S, Kalunian KC, İnanç M, van Vollenhoven R, Ramos-Casals M, Kamen DL, Jacobsen S, Peschken C, Askanase A, Stoll T (2016) Cardiovascular events prior to or early after diagnosis of systemic lupus erythematosus in the systemic lupus international collaborating clinics cohort. Lupus Sci Med 3(1):e000143

32. Crowson CS, Nicola PJ, Kremers HM, O'Fallon WM, Therneau TM, Jacobsen SJ, Roger VL, Ballman KV, Gabriel SE (2005) How much of the increased incidence of heart failure in rheumatoid arthritis is attributable to traditional cardiovascular risk factors and ischemic heart disease? Arthritis Rheumatol 52(10):3039-3044

33. Ma Y, Li L, Shao Y, Bai X, Bai T, Huang X (2017) Methotrexate improves perivascular adipose tissue/endothelial dysfunction via activation of AMPK/eNOS pathway. Mol Med Rep 15(4):2353-2359

34. Mavrogeni S, Dimitroulas T, Gabriel S, Sfikakis PP, Pohost GM, Kitas GD (2014) Why currently used diagnostic techniques for heart failure in rheumatoid arthritis are not enough: the challenge of cardiovascular magnetic resonance imaging. Rev Cardiovasc Med 15(4):320-3231

35. Mavrogeni SI, Kitas GD, Dimitroulas T, Sfikakis PP, Seo P, Gabriel S, Patel AR, Gargani L, Bombardieri S, Matucci-Cerinic M, Lombardi M, Pepe A, Aletras AH, Kolovou G, Miszalski T, van Riel P, Semb A, Gonzalez-Gay MA, Dessein P, Karpouzas G, Puntmann V, Nagel E, Bratis K, Karabela G, Stavropoulos E, Katsifis G, Koutsogeorgopoulou L, van Rossum A, Rademakers F, Pohost G, Lima JA (2016) Cardiovascular magnetic resonance in rheumatology: current status and recommendations for use. Int J Cardiol 217:135-148

36. Mavrogeni S, Sfikakis PP, Gialafos E, Bratis K, Karabela G, Stavropoulos E, Spiliotis G, Sfendouraki E, Panopoulos S, Bournia V, Kolovou G, Kitas GD (2014) Cardiac tissue characterization and the diagnostic value of cardiovascular magnetic resonance in systemic connective tissue diseases. Arthritis Care Res (Hoboken) 66(1):104-112

37. Mavrogeni S, Markousis-Mavrogenis G, Koutsogeorgopoulou L, Dimitroulas T, Bratis K, Kitas GD, Sfikakis P, Tektonidou M, Karabela G, Stavropoulos E, Katsifis G, Boki KA, Kitsiou A, Filaditaki V, Gialafos E, Plastiras S, Vartela V, Kolovou G (2017) Cardiovascular magnetic resonance imaging pattern at the time of diagnosis of treatment naïve patients with connective tissue diseases. Int J Cardiol 236:151-156

38. Chraibi S, Ibnabdeljalil H, Habbal R, Bennis A, Tahiri A, Chraibi N (1998) Pericardial tamponade as the first manifestation of dermatopolymyositis. Ann Med Interne (Paris) 149(7):464-466

39. Mavrogeni S, Bratis K, Sfendouraki E, Papadopoulou E, Kolovou G (2013) Myopericarditis, as the first sign of rheumatoid arthritis relapse, evaluated by cardiac magnetic resonance. Inflamm Allergy Drug Targets 12(3):206-211

40. Mavrogeni SI, Schwitter J, Gargani L, Pepe A, Monti L, Allanore Y, Matucci-Cerinic M (2017) Cardiovascular magnetic resonance in systemic sclerosis: "Pearls and pitfalls". Semin Arthritis Rheum 47(1):79-85. https://doi.org/10.1016/j.semarthrit.2017.03.020

41. Kouranos V, Tzelepis GE, Rapti A, Mavrogeni S, Aggeli K, Douskou M, Prasad S, Koulouris N, Sfikakis P, Wells A, Gialafos E (2017) Complementary role of CMR to conventional screening in the diagnosis and prognosis of cardiac sarcoidosis. JACC Cardiovasc Imaging 10(12):1437-1447. https://doi.org/10.1016/j. jcmg.2016.11.019

42. Raman SV, Aneja A, Jarjour WN (2012) CMR in inflammatory vasculitis. J Cardiovasc Magn Reson 14:82

43. Mavrogeni S, Sfikakis PP, Karabela G, Stavropoulos E, Spiliotis G, Gialafos E, Panopoulos S, Bournia V, Manolopoulou D, Kolovou G, Kitas G (2014) Cardiovascular magnetic resonance imaging in asymptomatic patients with connective tissue disease and recent onset left bundle branch block. Int J Cardiol 171(1):82-87

44. Kobayashi Y, Kobayashi H, Giles JT, Hirano M, Nakajima Y, Takei M (2016) Association of tocilizumab treatment with changes in measures of regional left ventricular function in rheumatoid arthritis, as assessed by cardiac magnetic resonance imaging. Int J Rheum Dis 19(11):1169-1174

45. Mayr A, Kitterer D, Latus J, Steubing H, Henes J, Vecchio F, Kaesemann P, Patrascu A, Greiser A, Groeninger S, Braun N, Alscher MD, Sechtem U, Mahrholdt H, Greulich S (2016) Evaluation of myocardial involvement in patients with connective tissue disorders: a multi-parametric cardiovascular magnetic resonance study. J Cardiovasc Magn Reson 18(1):67

46. Mavrogeni S, Markousis-Mavrogenis G, Koutsogeorgopoulou L, Kolovou G (2017) Cardiovascular magnetic resonance imaging: clinical implications in the evaluation of connective tissue diseases. J Inflamm Res 10:55-61

47. Mavrogeni S, Bratis K, Koutsogeorgopoulou L, Karabela G, Savropoulos E, Katsifis G, Raftakis J, Markousis-Mavrogenis G, Kolovou G (2017) Myocardial perfusion in peripheral Raynaud's phenomenon. Evaluation using stress cardiovascular magnetic resonance. Int J Cardiol 228:444-448

48. Muangchan C, van Vollenhoven RF, Bernatsky SR, Smith CD, Hudson M, Inanç M, Rothfield NF, Nash PT, Furie RA, Senécal JL, Chandran V, Burgos-Vargas R, Ramsey-Goldman R, Pope JE (2015) Treatment algorithms in systemic lupus erythematosus. Arthritis Care Res (Hoboken) 67(9):1237-1245

49. Mavrogeni S, Koutsogeorgopoulou L, Markousis-Mavrogenis G, Bounas A, Tektonidou M, Lliossis SC, Daoussis D, Plastiras S, Karabela G, Stavropoulos E, Katsifis G, Vartela V, Kolovou G (2017) Cardiovascular magnetic resonance detects silent heart disease missed by echocardiography in systemic lupus erythematosus. Lupus 1:961203317731533. https://doi.org/10.1177/09612 03317731533 
50. Hinojar R, Foote L, Sangle S, Marber M, Mayr M, Carr-White G, D'Cruz D, Nagel E, Puntmann VO (2016) Native T1 and T2 mapping by CMR in lupus myocarditis: disease recognition and response to treatment. Int J Cardiol 222:717-726

51. Zhang Y, Corona-Villalobos CP, Kiani AN, Eng J, Kamel IR, Zimmerman SL, Petri M (2015) Myocardial T2 mapping by cardiovascular magnetic resonance reveals subclinical myocardial inflammation in patients with systemic lupus erythematosus. Int J Cardiovasc Imaging 31(2):389-397

52. Sarzi-Puttini P, Atzeni F, Shoenfeld Y, Ferraccioli G (2005) TNFalpha, rheumatoid arthritis, and heart failure: a rheumatological dilemma. Autoimmun Rev 4(3):153-161

53. Mavrogeni S, Dimitroulas T, Gabriel S, Sfikakis PP, Pohost GM, Kitas GD (2014) Why currently used diagnostic techniques for heart failure in rheumatoid arthritis are not enough: the challenge of cardiovascular magnetic resonance imaging. Rev Cardiovasc Med 15(4):320-331

54. Kobayashi H, Kobayashi Y, Yokoe I, Akashi Y, Takei M, Giles JT (2017) Magnetic resonance imaging-detected myocardial inflammation and fibrosis in rheumatoid arthritis: associations with disease characteristics and $\mathrm{N}$-terminal pro-brain natriuretic peptide levels. Arthritis Care Res (Hoboken) 69(9):1304-1311

55. Kobayashi H, Kobayashi Y, Giles JT, Yoneyama K, Nakajima Y, Takei M (2014) Tocilizumab treatment increases left ventricular ejection fraction and decreases left ventricular mass index in patients with rheumatoid arthritis without cardiac symptoms: assessed using $3.0 \mathrm{~T}$ cardiac magnetic resonance imaging. J Rheumatol 41(10):1916-1921

56. Yogasundaram H, Putko BN, Tien J, Paterson DI, Cujec B, Ringrose J, Oudit GY (2014) Hydroxychloroquine-induced cardiomyopathy: case report, pathophysiology, diagnosis, and treatment. Can J Cardiol 30(12):1706-1715

57. Mavrogeni S, Kolovou G, Kitas G (2017) Cardiac involvement in ankylosing spondylitis. Can new magnetic resonance indices interpret cardiac pathophysiology beyond echocardiography? Heart 103(10):736-737

58. Biesbroek PS, Heslinga SC, Konings TC, van der Horst-Bruinsma IE, Hofman MBM, van de Ven PM, Kamp O, van Halm VP, Peters MJL, Smulders YM, van Rossum AC, Nurmohamed MT, Nijveldt R (2017) Insights into cardiac involvement in ankylosing spondylitis from cardiovascular magnetic resonance. Heart 103(10):745-752

59. Kahan A, Coghlan G, McLaughlin V (2009) Cardiac complications of systemic sclerosis. Rheumatology 48(Suppl 3):iii45-iii48

60. Konstantopoulou P, Gialafos E, Moyssakis I, Tountas C, Konsta M, Vaiopoulos G, Sfikakis PP (2016) Evolution and management of late onset cardiac involvement in a contemporary systemic sclerosis cohort. Mediterr J Rheumatol 27(3):34-40

61. Allanore Y, Meune C, Vonk MC, Airo P, Hachulla E, Caramaschi P, Riemekasten G, Cozzi F, Beretta L, Derk CT, Komócsi A, Farge D, Balbir A, Riccieri V, Distler O, Chialà A, Del Papa N, Simic KP, Ghio M, Stamenkovic B, Rednic S, Host N, Pellerito R, Zegers E, Kahan A, Walker UA, Matucci-Cerinic M, EUSTAR Co-authors (2010) Prevalence and factors associated with left ventricular dysfunction in the EULAR scleroderma trial and research group (EUSTAR) database of patients with systemic sclerosis. Ann Rheum Dis 69: 218-221

62. Hoffman GS, Merkel PA, Brasington RD, Lenschow DJ, Liang P (2004) Anti-tumor necrosis factor therapy in patients with difficult to treat Takayasu arteritis. Arthritis Rheumatol 50:2296-2304

63. Mavrogeni SI, Bratis K, Karabela G, Spiliotis G, Wijk KV, Hautemann D, Reiber JH, Koutsogeorgopoulou L, MarkousisMavrogenis G, Kolovou G, Stavropoulos E (2015) Cardiovascular magnetic resonance imaging clarifies cardiac pathophysiology in early, asymptomatic diffuse systemic sclerosis. Inflamm Allergy Drug Targets 14(1):29-36
64. Ntusi NA, Piechnik SK, Francis JM, Ferreira VM, Rai AB, Matthews PM, Robson MD, Moon J, Wordsworth PB, Neubauer S, Karamitsos TD (2014) Subclinical myocardial inflammation and diffuse fibrosis are common in systemic sclerosis - a clinical study using myocardial T1-mapping and extracellular volume quantification. J Cardiovasc Magn Reson 16:21

65. Pieroni M, De Santis M, Zizzo G, Bosello S, Smaldone C, Campioni M, De Luca G, Laria A, Meduri A, Bellocci F, Bonomo L, Crea F, Ferraccioli G (2014) Recognizing and treating myocarditis in recent-onset systemic sclerosis heart disease: potential utility of immunosuppressive therapy in cardiac damage progression. Semin Arthritis Rheumatol 43(4):526-535

66. Molloy ES, Langford CA, Clark TM, Gota CE, Hoffman GS (2008) Anti-tumour necrosis factor therapy in patients with refractory Takayasu arteritis: long-term follow-up. Ann Rheum Dis 67:1567-1569

67. Iwagaitsu S, Naniwa $T$ (2017) Improvement of arterial wall lesions in parallel with decrease of plasma pentraxin-3 levels in a patient with refractory Takayasu arteritis after treatment with tocilizumab. Case Rep Rheumatol 2017:4580967

68. Loricera J, Blanco R, Hernández JL, Castañeda S, Humbría A, Ortego N, Bravo B, Freire M, Melchor S, Mínguez M, Salvatierra J, González-Vela C, Calvo-Río V, Santos-Gómez M, Pina T, González-Gay MA (2016) Tocilizumab in patients with Takayasu arteritis: a retrospective study and literature review. Clin Exp Rheumatol 34(3 Suppl 97):S44-S53

69. Lie JT (1995) Aortic and extracranial large vessel giant cell arteritis: a review of 72 cases with histopathologic documentation. Semin Arthritis Rheumatol 24:422-431

70. Nesher GN, Berkun Y, Mates M, Baras M, Rubinow A, Sonnenblick M (2004) Low-dose aspirin and prevention of cranial ischemic complications in GCA. Arthritis Rheumatol 50:1332-1337

71. Keenan NG, Mason JC, Maceira A, Assomull R, O’Hanlon R, Chan C, Roughton M, Andrews J, Gatehouse PD, Firmin DN, Pennell DJ (2009) Integrated cardiac and vascular assessment in Takayasu arteritis by cardiovascular magnetic resonance. Arthritis Rheumatol 60(11):3501-3509

72. Roghi A, Pedrotti P, Milazzo A, Vignati G, Martinelli L, Paino R, Bonacina E (2010) Acute myocardial infarction and cardiac arrest in atypical Takayasu aortitis in a young girl: unusual diagnostic role of cardiac magnetic resonance imaging in emergency setting. Circulation 121(14):e370-e375

73. Lee MS, Smith SD, Galor A, Hoffman GS (2006) Antiplatelet and anticoagulant therapy in patients with giant cell arteritis. Arthritis Rheumatol 54:3306-3309

74. Bechman K, Gopalan D, Nihoyannopoulos P, Mason JC (2017) A cohort study reveals myocarditis to be a rare and life-threatening presentation of large vessel vasculitis. Semin Arthritis Rheumatol 47(2):241-246

75. Mavrogeni S, Papadopoulos G, Hussain T, Chiribiri A, Botnar R, Greil GF (2013) The emerging role of cardiovascular magnetic resonance in the evaluation of Kawasaki disease. Int J Cardiovasc Imaging 29(8): 1787-1798

76. Davison AG, Thompson PJ, Davies J, Corrin B, Turner-Warwick M (1983) Prominent pericardial and myocardial lesions in the Churg-Strauss syndrome (allergic granulomatosis and angiitis). Thorax 38:793-795

77. Schiefermueller J, Alaour B, Calver A, Curzen N (2017) Lesson of the month 1: beware the atypical presentation: eosinophilic granulomatosis with polyangiitis presenting as acute coronary syndrome. Clin Med (Lond) 17(2):180-182

78. Fijolek J, Wiatr E, Gawryluk D, Nowicka U, Martusewicz-Boros MM, Kober J, Piotrowska-Kownacka D, Roszkowski-Sliz K (2016) The significance of cardiac magnetic resonance imaging in detection and monitoring of the treatment efficacy of heart 
involvement in eosinophilic granulomatosis with polyangiitis patients. Sarcoidosis Vasc Diffuse Lung Dis 33(1):51-58

79. Miszalski-Jamka T, Szczeklik W, Sokołowska B, Karwat K, Miszalski-Jamka K, Jaźwiec P, Małek ŁA, Al-Khalidi H, SchulzMenger J, Mavrogeni S, Mahr A, Mazur W, Kereiakes DJ, Musiał J (2015) Noncorticosteroid immunosuppression limits myocardial damage and contractile dysfunction in eosinophilic granulomatosis with polyangiitis (Churg-Strauss syndrome). J Am Coll Cardiol 65(1):103-105

80. Cereda AF, Pedrotti P, De Capitani L, Giannattasio C, Roghi A (2017) Comprehensive evaluation of cardiac involvement in eosinophilic granulomatosis with polyangiitis (EGPA) with cardiac magnetic resonance. Eur J Intern Med 39:51-56

81. Yune S, Choi DC, Lee BJ, Lee JY, Jeon ES, Kim SM, Choe YH (2016) Detecting cardiac involvement with magnetic resonance in patients with active eosinophilic granulomatosis with polyangiitis. Int J Cardiovasc Imaging 32(Suppl 1):155-162

82. Hazebroek MR, Kemna MJ, Schalla S, Sanders-van Wijk S, Gerretsen SC, Dennert R, Merken J, Kuznetsova T, Staessen JA, Brunner-La Rocca HP, van Paassen P, Cohen Tervaert JW, Heymans S (2015) Prevalence and prognostic relevance of cardiac involvement in ANCA-associated vasculitis: eosinophilic granulomatosis with polyangiitis and granulomatosis with polyangiitis. Int J Cardiol 199:170-179

83. Mathai SC, Hassoun PM (2012) Pulmonary arterial hypertension in connective tissue diseases. Heart Fail Clin 8(3):413-425

84. Baggen VJ, Leiner T, Post MC, van Dijk AP, Roos-Hesselink JW, Boersma E, Habets J, Sieswerda GT (2016) Cardiac magnetic resonance findings predicting mortality in patients with pulmonary arterial hypertension: a systematic review and meta-analysis. Eur Radiol 26(11):3771-3780

85. Addetia K, Bhave NM, Tabit CE, Gomberg-Maitland M, Freed BH, Dill KE, Lang RM, Mor-Avi V, Patel AR (2014) Sample size and cost analysis for pulmonary arterial hypertension drug trials using various imaging modalities to assess right ventricular size and function end points. Circ Cardiovasc Imaging 7(1):115-124

86. Wilkins MR, Paul GA, Strange JW, Tunariu N, Gin-Sing W, Banya WA, Westwood MA, Stefanidis A, Ng LL, Pennell DJ, Mohiaddin RH (2005) Sildenafil versus endothelin receptor antagonist for pulmonary hypertension (SERAPH) study. AJ RCCM 171:1

87. Hassoun PM, Zamanian RT, Damico R, Lechtzin N, Khair R, Kolb TM, Tedford RJ, Hulme OL, Housten T, Pisanello C, Sato T, Pullins EH, Corona-Villalobos CP, Zimmerman SL, Gashouta MA, Minai OA, Torres F, Girgis RE, Chin K, Mathai SC (2015) Ambrisentan and tadalafil up-front combination therapy in scleroderma-associated pulmonary arterial hypertension. Am J Respir Crit Care Med 192(9):1102-1110

88. Ponikowski P, Voors AA, Anker SD, Bueno H, Cleland JG, Coats AJ, Falk V, González-Juanatey JR, Harjola VP, Jankowska EA, Jessup M, Linde C, Nihoyannopoulos P, Parissis JT, Pieske B, Riley JP, Rosano GM, Ruilope LM, Ruschitzka F, Rutten FH, van der Meer P, Authors/Task Force Members; Document Reviewers (2016) 2016 ESC Guidelines for the diagnosis and treatment of acute and chronic heart failure: The Task Force for the diagnosis and treatment of acute and chronic heart failure of the European Society of Cardiology (ESC). Developed with the special contribution of the Heart Failure Association (HFA) of the ESC. Eur J Heart Fail 18(8):891-975

89. Escher F, Kühl U, Lassner D, Poller W, Westermann D, Pieske B, Tschöpe C, Schultheiss HP (2016) Long-term outcome of patients with virus-negative chronic myocarditis or inflammatory cardiomyopathy after immunosuppressive therapy. Clin Res Cardiol 105(12):1011-1020

90. Cooper LT, Hare JM, Tazelaar HD, Edwards WD, Starling RC, Deng MC, Menon S, Mullen GM, Jaski B, Bailey KR, Cunningham MW, Dec GW, Giant Cell Myocarditis Treatment Trial Investigator (2008) Usefulness of immunosuppression for giant cell myocarditis. Am J Cardiol 102(11):1535-1539

\section{Affiliations}

\section{Sophie I. Mavrogeni ${ }^{1}$. Petros P. Sfikakis ${ }^{2}$. Theodoros Dimitroulas ${ }^{3} \cdot$ Loukia Koutsogeorgopoulou $^{4} \cdot$ Gikas Katsifis $^{5}$. George Markousis-Mavrogenis ${ }^{1}$. Genovefa Kolovou ${ }^{1}$. George D. Kitas ${ }^{6}$}

Petros P. Sfikakis

psfikakis@med.uoa.gr

Theodoros Dimitroulas

dimitroul@gmail.com

Loukia Koutsogeorgopoulou

lukia.km@gmail.com

Gikas Katsifis

katsifisg@yahoo.gr

George Markousis-Mavrogenis

georgemm32@gmail.com

Genovefa Kolovou

genovefa@kolovou.com

George D. Kitas

Kitas@dgh.nhs.uk
1 Onassis Cardiac Surgery Center, 50 Esperou Street, P. Faliro, 175-61 Athens, Greece

2 First Department of Propaedeutic and Internal Medicine, National and Kapodisstrian University of Athens Medical School, Athens, Greece

3 4th Department of Internal Medicine, Hippokration University Hospital, Medical School, Aristotle University of Thessaloniki, Thessaloniki, Greece

4 Pathophysiology Department, National and Kapodisstrian University of Athens Medical School, Athens, Greece

5 Naval Hospital, Athens, Greece

6 Arthritis Research UK Epidemiology Unit, Manchester University, Manchester, UK 